\title{
Impact of COVID-19 on mental health and psychosocial support services in the Eastern Mediterranean Region - results of a rapid assessment
}

Wafaa Elsawy, ${ }^{1}$ Heba Fouad ${ }^{1}$ and Khalid Saeed ${ }^{1}$

'WHO Regional Office for the Eastern Mediterranean, Cairo, Egypt (Correspondence to: Wafaa Elsawy: elsawyw@who.int)

\begin{abstract}
Background: Mental health has been identified by the World Health Organization as an integral component of the COVID-19 response.

Aims: This study aimed to estimate the impact of COVID-19 pandemic on mental, neurological and substance use disorders (MNS) services in the Eastern Mediterranean Region.

Methods: The assessment was conducted through a web-based survey that was completed by national mental health focal persons and was analysed between June and August 2020.

Results: School and workplace mental health services were wholly or partially disrupted in more than $70 \%$ of reporting countries. Fewer than $20 \%$ of the countries in the Region reported full operations of mental health services for children and adolescents or for older adults. The main reasons were travel restrictions, decreases in inpatient volumes due to the cancellation of elective care, decreases in outpatient volumes due to patients not presenting, and health authority directives for the closure of outpatient services. The majority $(85 \%)$ of countries responded by establishing MNS helplines using telemedicine/teletherapy and digital psychological interventions. The fragile and conflict-affected states relied mostly on implementing infection prevention and control measures at MNS service facilities. Gaps were identified in the areas of addictive behaviours, substance use and neurology research related to the pandemic.
\end{abstract}

Conclusion: The assessment highlights the need to strengthen capacities for monitoring changes in service delivery and utilization, and documents evidence on what works in different settings during the different phases of the pandemic to facilitate informed decisions related to the nature and timing of adaptations to service delivery.

Keywords: COVID-19, MNS services, disruption, response, EMR countries

Citation: Elsawy W; Fouad H; Saeed K. Impact of COVID-19 on mental health and psychosocial support services in the Eastern Mediterranean Region results of a rapid assessment. East Mediterr Health J. 2022;28(5):321-328. https://doi.org/10.26719/emhj.22.018

Received: 08/04/21; accepted: 14/10/21

Copyright $\odot$ World Health Organization (WHO) 2022. Open Access. Some rights reserved. This work is available under the CC BY-NC-SA 3.0 IGO license (https://creativecommons.org/licenses/by-nc-sa/3.o/igo).

\section{Introduction}

On 30 January 2020, the World Health Organization (WHO) declared the novel coronavirus outbreak (COVID-19) as a Public Health Emergency of International Concern (1). Globally, more than 170 million confirmed COVID-19 cases, including over 3 million deaths, and regionally, more than 10 million and 200000 confirmed cases and deaths, respectively, had been reported to WHO by 2 June 2021 (2). The COVID-19 pandemic has not only led to morbidity and mortality but has also resulted in widespread emotional and psychological distress as evidenced from a number of national surveys in 2020 (3-5). Furthermore, higher than usual levels of symptoms of depression and anxiety have been recorded in various countries. A large study in Ethiopia in April 2020 reported an estimated 33\% prevalence rate for symptoms consistent with depressive disorder (6), a 3 -fold increase compared with national estimates before the epidemic (7). Regionally, a study conducted in Egypt showed that during the first 4 months of the pandemic the percentage of cases presenting with depression, anxiety disorders, substance use disorders and obsessive- compulsive disorders increased (8). Along with increased rates of distress and mental, neurological and substance use disorders (MNS), services for MNS disorders have been adversely impacted by COVID-19 due to increasing demands, risk and fear of infection, movement restrictions creating barriers to meeting people face-toface, closing of facilities or converting them into care facilities for people with COVID-19, mental health staff being infected with the virus (9), and insufficient staff (10). These factors also contribute to the exacerbation or relapse of existing MNS disorders such as depression, generalized anxiety disorder, chronic insomnia and even suicide as well as precipitating MNS disorders (1).

In the Eastern Mediterranean Region (EMR), some countries are already facing protracted emergencies, with the Region hosting one of the largest internally displaced and refugee/migrant populations in the world; such populations are likely to have higher rates of MNS disorders than the general population (11). They had to contend with reduced economic activities and employment opportunities due to the mitigation measures put into place to limit the spread 
of COVID-19. This resulted in an increase in poverty rates and difficulties in applying public health measures like physical distancing, quarantine and self-isolation, which rendered the populations affected even more vulnerable to developing MNS disorders (1). Moreover, frontline health care workers in particular experienced additional stressors during the COVID-19 pandemic, such as stigmatization, strict biosecurity measures, high workloads and long working hours, decreased opportunities for seeking social support and the fear of passing COVID-19 to friends and family (12). Recently, the emergence of new COVID-19 variants, myths and fear regarding newly available vaccines, multiple vaccine options, potential side-effects and distribution logistics, which might be a challenge for several countries in the Region, have all led to prolonged psychological distress caused by the virus.

While COVID-19 has taken a toll on health systems around the world, leading to the disruption of essential services delivery, especially for the most vulnerable populations, it has especially highlighted the chronic neglect of mental health services in many countries.

In order to understand the impact on service delivery for MNS disorders, WHO embarked on a rapid assessment of service delivery for mental, neurological and substance use disorders during the COVID-19 pandemic to measure the impact on MNS services at global and regional levels. The results of the regional survey provide an overview of the impacts of COVID-19 on MNS services and an analysis of the reasons for disruptions. The findings will inform planning and response to mitigate the effects of the pandemic on populations and communities, tailored and adapted to the regional specificities and context.

\section{Methods}

\section{Overview}

The survey questionnaire was administered in the Region through the mental health unit of the WHO Regional Office for the Eastern Mediterranean and was completed by mental health focal points within each country's ministry of health or national agency responsible for mental health. The response rate was $91 \%$ ( 20 out of 22 countries in the Region).

\section{Survey tool: web-based questionnaire}

The WHO Department of Mental Health and Substance Use developed the survey "Rapid assessment of service delivery for mental, neurological and substance use disorders during the COVID-19 pandemic" in collaboration with the 6 WHO regional offices. The survey followed the template of a recent WHO survey on the impact of COVID-19 on noncommunicable disease resources and services but adapted its structure and scope to mental health (13). The questionnaire comprised 9 multiple choice questions designed to assess theinclusion of mental health and psychosocial support (MHPSS) response in national COVID-19 response plans; additional funding for MHPSS in national COVID-19 response plans; multisectoral
MHPSS coordination platforms for COVID-19 response; government policies for access to essential MNS services included in national COVID-19 responses; level of MNS interventions/service disruptions due to COVID-19; main reasons for service disruptions; approaches to overcoming service disruptions for the management of MNS disorders and provision of MHPSS services; data collection on MNS disorders/ manifestations in people with COVID-19; and studies conducted on the impact of COVID-19 on mental health/ brain health/substance use.

\section{Statistical analysis}

Data were analysed using SPSS and Microsoft Excel software. They were summarized as a percentage of either the total number of countries which responded to the survey or as a percentage of their corresponding country group; these groups have been categorized based on population health outcomes, health system performance and level of health expenditure (14). Group 1 comprised countries where socioeconomic development has progressed considerably over recent decades, supported by high incomes (Bahrain, Kuwait, Oman, Qatar, Saudi Arabia and United Arab Emirates). Group 2 comprised largely middle-income countries which have developed extensive public health service delivery infrastructure but which still face resource constraints (Egypt, Islamic Republic of Iran, Iraq, Jordan, Lebanon, Libya, Morocco, Tunisia and West Bank and Gaza Strip). Group 3 comprised countries which face major constraints in improving population health outcomes as a result of lack of resources for health, political instability and other complex development challenges (Afghanistan, Pakistan, Somalia, Sudan and Yemen). Further analysis was conducted for 5 countries in the Region that were facing complex emergency situations (fragile and conflict-affected states, or FCS): Iraq, Libya, Somalia, Sudan and Yemen.

\section{Results}

In response to the COVID-19 outbreak, countries in the Region developed national action plans to address the unprecedented and rapidly changing health needs of their populations. Most of the EMR countries (19/20) reported having MHPSS components included in the national response to COVID-19 (Table 1). Regarding additional funding allocated for MHPSS in government budgets for COVID-19, only 1 of the 6 countries in Group 1 reported that the MHPSS component was fully funded by the government. In Group 3, only 1 of the 5 countries reported partial funding; and in Group 2, 8 of the 9 countries reported that MHPSS response was not funded at all. Further analysis of the EMR countries reveals that a clear majority (4/5) of the fragile and conflict-affected states had no governmental funding for MHPSS (Table 1).

The majority $(75 \%)$ of countries reported having an MHPSS coordination platform for COVID-19 response. More than half (55\%) reported that all MNS services were 


\begin{tabular}{|c|c|c|c|c|c|}
\hline \multirow[t]{3}{*}{ Policy/plan } & \multicolumn{5}{|c|}{ EMR countries } \\
\hline & Group $1^{\mathrm{a}}$ & Group $2^{\mathbf{b}}$ & Group $3^{c}$ & FCS $^{d}$ & EMR $^{\mathbf{e}}$ \\
\hline & No. (\%) & No. (\%) & No. (\%) & No. (\%) & No. (\%) \\
\hline \multicolumn{6}{|c|}{ Integration of MHPSS as part of COVID-19 response plans } \\
\hline Yes & $5(83.3)$ & $9(100.0)$ & $5(100.0)$ & $5(100.0)$ & $19(95.0)$ \\
\hline Don't know & $1(16.7)$ & - & - & - & $1(5.0)$ \\
\hline \multicolumn{6}{|c|}{ Additional funding allocated for MHPSS in government budget for COVID-19 } \\
\hline Fully funded & $1(16.7)$ & $1(11.1)$ & - & - & $2(10.0)$ \\
\hline Partially funded & $3(50.0)$ & - & $1(20.0)$ & $1(20.0)$ & $4(20.0)$ \\
\hline Not funded & $1(16.7)$ & $8(88.8)$ & $4(80.0)$ & $4(80.0)$ & $13(65.0)$ \\
\hline Don't know & - & - & - & - & - \\
\hline \multicolumn{6}{|c|}{ Multisectoral MHPSS coordination platform for COVID-19 response } \\
\hline Yes & $4(66.7)$ & $6(66.7)$ & $5(100.0)$ & $4(80.0)$ & $15(75.0)$ \\
\hline No & $1(16.7)$ & $3(33.3)$ & - & $1(20.0)$ & $4(20.0)$ \\
\hline Don’t know & $1(16.7)$ & - & - & - & $1(5.0)$ \\
\hline \multicolumn{6}{|c|}{ Integration of MNS services in list of essential health services during COVID-19 response plan } \\
\hline All MNS services & $4(66.7)$ & $6(66.7)$ & $1(20.0)$ & - & $11(55.0)$ \\
\hline Some MNS services & $2(33.3)$ & $1(11.1)$ & $3(60.0)$ & $3(60.0)$ & $6(30.0)$ \\
\hline No MNS services & - & $2(22.2)$ & $1(20.0)$ & $2(40.0)$ & $3(15.0)$ \\
\hline \multicolumn{6}{|c|}{ Studies/research related to impact of COVID-19 pandemic on the following: } \\
\hline Mental health impact & $3(50.0)$ & $7(77.8)$ & $3(60.0)$ & $3(60.0)$ & $13(65.0)$ \\
\hline Neurological disorders or brain health ${ }^{\mathrm{a}}$ & - & - & - & - & - \\
\hline Alcohol consumption & - & - & - & - & - \\
\hline Psychoactive drugs & $1(16.7)$ & - & - & - & $1(5.0)$ \\
\hline Other addictive behaviours ${ }^{\mathrm{a}}$ & - & - & - & - & - \\
\hline No study/research conducted & - & $1(11.1)$ & - & $1(20.0)$ & $2(10.0)$ \\
\hline
\end{tabular}

MNS = mental, neurological and substance use disorders.

Group 1: Bahrain, Kuwait, Oman, Qatar, Saudi Arabia, United Arab Emirates.

Group 2: Egypt, Islamic Republic of Iran, Iraq, Jordan, Lebanon, Libya, Morocco, Tunisia, occupied Palestinian territories (West Bank and Gaza Strip). Group 3: Afghanistan, Pakistan, Somalia, Sudan, Yemen.

FCS = fragile and conflict-affected states: Iraq, Libya, Somalia, Sudan, Yemen.

$E M R=$ all EMR countries except Djibouti and Syrian Arab Republic.

${ }^{a}$ None of the responding countries conducted studies/research related to the impact of the COVID-19 pandemic on either neurological disorders or brain.

included in their list of essential health services (Table 1). Two-thirds (66.7\%) of Group 1 and Group 2 countries reported the inclusion of all MNS services in the list, while only $20 \%$ of Group 3 countries did so. None of the fragile and conflict-affected states in the Region had all types of MNS services included in their essential health services list.

Countries also reported on national-level governmental policies for access to essential services for MNS disorders, including inpatient and outpatient services at mental hospitals; inpatient and outpatient services in general hospitals; and community-level services for MNS disorders, such as in primary health care and residential, home and day care services. Regarding access to community-based essential services for MNS disorders, 50\% (7/14) EMR countries reported complete closure of day care services and $45.5 \%$ (5/11) reported complete closure of home care services. At the secondary care level, outpatient services, psychiatric inpatient units, neurology inpatient units and inpatient units for substance use disorders were operational in $38.9 \%(7 / 18), 38.9 \%(7 / 18), 30.8 \%(4 / 13)$ and $40 \%(6 / 15)$ of countries, respectively (Table 2 ). Regarding mental health hospitals, outpatient services were open in 9 (45\%) and inpatient services in 11 (55\%) of the reporting countries. Regionally, none of the reporting countries had all types of MNS services either fully operational or fully closed.

The assessment shows high levels of disruption of essential MNS services in countries in the Region. The most disrupted services [completely (more than 50\% of inpatients not treated as usual) and partially (5\% to $50 \%$ of inpatients not treated as usual)] were community/ outreach services for people with MNS disorders (88.9\%), surgery for neurological disorders (88.2\%), psychotherapy/ counselling/psychosocial interventions (85\%), school mental health programmes $(83.3 \%)$, and services for children and older adults with mental health conditions or disabilities (83.3\%) (Table 3). On the other hand, almost two-thirds $(62.3 \%)$ of the countries in the EMR reported 


\begin{tabular}{|c|c|c|c|}
\hline \multirow[t]{2}{*}{ Cause of disruption } & \multicolumn{3}{|c|}{$\begin{array}{l}\text { Level of access to essential services } \\
\text { (\% of countries) }\end{array}$} \\
\hline & Closed & Partially open & Open \\
\hline \multicolumn{4}{|l|}{ Tertiary-level care } \\
\hline Residential services & 7.1 & 42.9 & 35.7 \\
\hline Services for MNS disorders & 13.3 & 40.0 & 33.3 \\
\hline Home care services & 45.5 & 27.3 & 18.2 \\
\hline Day care services & 50.0 & 35.7 & 7.1 \\
\hline \multicolumn{4}{|l|}{ Secondary-level care } \\
\hline Substance use disorder inpatient units & 26.7 & 33.3 & 40.0 \\
\hline Neurology inpatient units & 69.2 & 30.8 & - \\
\hline Psychiatric inpatient units & 11.1 & 50.0 & 38.9 \\
\hline Outpatient services for MNS disorders & 16.7 & 44.4 & 39.9 \\
\hline \multicolumn{4}{|l|}{ Primary-level care } \\
\hline Inpatient services & - & 45.0 & 55.0 \\
\hline Outpatient services & - & 55.0 & 45.0 \\
\hline
\end{tabular}

that supplies of medicines for MNS disorders services were not disrupted.

The main reasons reported for MNS service disruption included travel restrictions (70\%), decreases in inpatient numbers due to cancellation of elective care (60\%), decreases in outpatient numbers due to patients not presenting (55\%), health authority directives for the closure of outpatient services (50\%) and health authority directives for the closure of disease-specific outpatient clinics (45\%) (Table 4). Unavailability of inpatient services and hospital beds was the most common cause of service disruption in Group 1 countries in the EMR; travel restrictions and closure of outpatient services as per health authority directives were the leading causes of disruption in Group 2 countries; and travel restrictions and decreases in inpatient numbers due to cancellation of elective care were the most common causes in Group 3 countries. Similarly, in addition to travel restrictions and cancellation of elective care, unavailability of essential medicines and medical diagnostics was the most common reason for MNS service disruptions in the fragile and conflict-affected states.

The analysis shows that multiple innovative interventions and approaches were being used to overcome service disruptions and to provide MHPSS during the COVID-19 pandemic. A majority (85\%) of countries had established helplines for MHPSS, had resorted to telemedicine and teletherapy to replace in-person consultations (80\%) and had discharged or redirected patients to alternative facilities (70\%) and to self-help or digital psychological interventions (65\%) (Table 5). In Groups 1, 2 and 3, a majority of countries had established helplines for MHPSS (100\%, 88.9\% and 60\% respectively). Implementation of infection prevention and control measures, discharge of patients or their redirection to alternative health care facilities, and basic psychosocial skills training for health care providers working in COVID-19 treatment centres were the

Table 3 Distribution of countries of the WHO Eastern Mediterranean Region which experienced complete or partial disruption to mental, neurological and substance userelated services/interventions during COVID-19 pandemic (June-July 2020)

\begin{tabular}{lc} 
Service/intervention disrupted & Countries (\%) \\
\hline Medicines for MNS disorders & 36.8 \\
Management of emergency MNS manifestations & 45.0 \\
Surgery for neurological disorders & 88.2 \\
Diagnostic and laboratory services & 63.2 \\
Critical harm reduction services & 66.7 \\
Overdose prevention and management & 70.6 \\
programmes & \\
Opioid agonist maintenance treatment of opioid & 46.7 \\
dependence & \\
Antenatal and postnatal period interventions & 75.0 \\
Interventions for caregivers of people with MNS & 76.5 \\
disorders & \\
Children and adolescents services & 83.3 \\
Older adults with mental health conditions or & 83.3 \\
disabilities & \\
Psychotherapy/counselling/psychosocial & 85.0 \\
interventions & \\
Home or community outreach services & 88.9 \\
Suicide prevention programmes & 72.2 \\
Work-related mental health programmes & 73.3 \\
School mental health programmes & 83.3 \\
\hline
\end{tabular}




\begin{tabular}{|c|c|c|c|c|c|}
\hline \multirow[t]{2}{*}{ Cause of disruption } & \multicolumn{5}{|c|}{ Country group (\% of countries) } \\
\hline & Group 1 & Group 2 & Group 3 & FCS & EMR \\
\hline Travel restrictions & 50.0 & 77.8 & 80.0 & 80.0 & 80.0 \\
\hline $\begin{array}{l}\text { Unavailability/stock-out of essential medicines, medical } \\
\text { diagnostics or health products }\end{array}$ & - & 33.3 & 40.0 & 80.0 & 25.0 \\
\hline Insufficient PPE available for health care providers & - & 22.2 & 40.0 & 60.0 & 20.0 \\
\hline Designation of clinical setup as COVID-19 care facility & 16.7 & 33.3 & - & 20.0 & 20.0 \\
\hline MNS clinical staff deployed to provide COVID-19 clinical support & 33.3 & 11.1 & 20.0 & - & 20.0 \\
\hline Insufficient staff & 16.7 & 44.4 & 40.0 & 40.0 & 35.0 \\
\hline Inpatient services/hospital beds not available & - & 22.2 & - & 20.0 & 10.0 \\
\hline Decrease in outpatient volumes due to patients not presenting & 83.3 & 44.4 & 60.0 & 80.0 & 60.0 \\
\hline Decrease in inpatient volumes due to cancellation of elective care & 66.7 & 55.6 & 40.0 & 60.0 & 55.0 \\
\hline $\begin{array}{l}\text { Closure of population-level programmes as per health authority } \\
\text { directive }\end{array}$ & 50.0 & 33.3 & 20.0 & 40.0 & 35.0 \\
\hline $\begin{array}{l}\text { Closure of outpatient disease-specific consultation clinics as per } \\
\text { health authority directive }\end{array}$ & 66.7 & 44.4 & 20.0 & 20.0 & 45.0 \\
\hline Closure of outpatient services as per health authority directive & 50.0 & 66.7 & 20.0 & 20.0 & 50.0 \\
\hline
\end{tabular}

Group 1: Bahrain, Kuwait, Oman, Oatar, Saudi Arabia and United Arab Emirates.

Group 2: Egypt, Islamic Republic of Iran, Iraq, Jordan, Lebanon, Libya, Morocco, Tunisia and West Bank and Gaza Strip.

Group 3: Afghanistan, Pakistan, Somalia, Sudan and Yemen.

FCS (fragile and conflict-affected states): Iraq, Libya, Somalia, Sudan and Yemen.

$E M R=$ all countries of the Eastern Mediterranean Region except Djibouti and Syrian Arab Republic.

$P P E=$ personal protective equipment.

approaches most commonly used to overcome service disruptions in the fragile and conflict-affected states.

As part of COVID-19 monitoring efforts, just over half the countries surveyed (55\%) reported collecting or collating data on MNS disorders or manifestations in people with COVID-19. More than two-thirds of EMR countries reported having planned or ongoing studies on the impacts of COVID-19 on mental health (by government or academia/civil society, either standalone or as part of a broader survey). However, only Oman reported having a planned/ongoing study on the impact of the use of psychoactive drugs in patients with COVID-19 (Table 1).

\section{Discussion and conclusion}

This assessment identified that most affected in the Region were the community outreach services, psychotherapy/counselling/psychosocial interventions, school mental health programmes, and services for children and older adults with mental health conditions or disabilities, which were already scarce. Globally, the level of disruption of these services was slightly lower (13). This will likely have a negative impact on the mental health of these vulnerable sections of the population. Although the countries are in the process of adapting their mental health systems to provide continuity of care for persons living with mental health problems, service disruptions occurred.

The most common factors for the disruption of services in the Region are comparable to those observed at the global level. However, decreases in outpatient numbers due to patients not presenting was the leading cause followed by travel restrictions and decreases in inpatient numbers due to cancellation of elective care (13). The mitigation strategies adopted in the countries of EMR are similar to the approaches reported globally (13).

While the use of technology to provide MHPSS interventions remotely has shown some evidence of short-term success $(15,16)$, it may also have longer-term advantages, especially in countries with low capacities and low levels of investment in mental health services (17). These approaches do have some drawbacks or challenges to implementation, such as the lack of evidence base for many popular counslling programmes, e.g. psychological debriefing sessions - and when delivered by under-skilled and unsupervised personnel, these may be harmful (18). Lack of access to technology or limited knowledge of using it such as by elderly individuals or people with disabilities, limited internet access and its cost, and data security and privacy are also areas of concern in scaling up such interventions $(18,19)$.

In the Region, close to half of the national monitoring and surveillance systems are not collecting any data on MNS disorders or manifestations in COVID-19 patients, which is similar to globally reported figures (13).

This survey provides insights from mental health focal points within ministries of health on the extent of disruptions to services for MNS disorders, and is an indication of their experience in adopting strategies to mitigate the impact on service provision. There were differences in the types of service disrupted; against a background of already scarce community mental health services, mental health prevention and promotion programmes were predominantly the most affected. The 
Table 5 Distribution of countries of the WHO Eastern Mediterranean Region (EMR) according to complete and partial disruption of mental, neurological and substance use (MNS)-related services/interventions during COVID-19 pandemic (June-July 2020)

\begin{tabular}{|c|c|c|c|c|c|}
\hline \multirow[t]{2}{*}{ Approach } & \multicolumn{5}{|c|}{ Country group (\% of countries) } \\
\hline & Group 1 & Group 2 & Group 3 & FCS & EMR \\
\hline Home or community outreach services & 16.7 & 22.2 & 40.0 & 40.0 & 25.0 \\
\hline Recruitment of additional counsellors & 33.3 & 22.2 & 40.0 & 20.0 & 30.0 \\
\hline Triaging to identify priorities & 83.3 & 22.2 & - & 20.0 & 35.0 \\
\hline Task shifting/role delegation & 66.7 & 33.3 & 40.0 & 20.0 & 45.0 \\
\hline $\begin{array}{l}\text { Health care providers working in COVID-19 treatment centres } \\
\text { trained in basic psychosocial skills }\end{array}$ & 33.3 & 44.4 & 80.0 & 80.0 & 50.0 \\
\hline Novel supply chain and/or dispensing approaches & 100 & 44.4 & 20.0 & 20.0 & 55.0 \\
\hline $\begin{array}{l}\text { Implementation of specific infection prevention control (IPC) } \\
\text { measures }\end{array}$ & 66.7 & 66.7 & 60.0 & 80.0 & 65.0 \\
\hline Self-help or digital format & 83.3 & 55.6 & 60.0 & 60.0 & 65.0 \\
\hline $\begin{array}{l}\text { Redirection of patients to alternate health care facilities or } \\
\text { discharge to their homes/families }\end{array}$ & 100 & 55.6 & 60.0 & 80.0 & 70.0 \\
\hline Telemedicine/teletherapy & 83.3 & 77.8 & 80.0 & 80.0 & 80.0 \\
\hline Helplines established for MHPSS & 100 & 88.9 & 60.0 & 60.0 & 85.0 \\
\hline
\end{tabular}

Group 1: Bahrain, Kuwait, Oman, Qatar, Saudi Arabia and United Arab Emirates.

Group 2: Egypt, Islamic Republic of Iran, Iraq, Jordan, Lebanon, Libya, Morocco, Tunisia and West Bank and Gaza Strip.

Group 3: Afghanistan, Pakistan, Somalia, Sudan and Yemen.

FCS (fragile and conflict-affected states): Iraq, Libya, Somalia, Sudan and Yemen.

$E M R=$ all EMR countries except Djibouti and Syrian Arab Republic.

MHPSS = mental health and psychosocial support.

results clearly indicate that, while global advocacy for the inclusion of mental health in COVID-19 responses has resulted in better integration into plans, multisectoral coordination platforms, innovative methods being applied in many countries through teleservices and helplines to overcome access barriers and the regular collection of data, there is still a gap in the financial and human resources allocated to integrate mental health into emergency response. This constitutes a significant challenge and a barrier to the continuity of services.

The COVID-19 pandemic highlights the value of including MHPSS not only in response to emergencies and recovery but also integration into preparedness plans and efforts (20). While many countries are implementing WHO-recommended strategies to mitigate disruptions to services, more information is needed to identify the long-term impacts of COVID-19 on mental health and substance use, the cost-effectiveness of online service delivery platforms and the feasibility of technological solutions for overcoming the barriers to access to mental health services. Strengthening national capacities to monitor changes in service delivery and utilization also need to be prioritized along with documenting evidence on what works in different settings during the different phases of the pandemic to facilitate informed decisions on the nature and timing of adaptations to service delivery.

Certain limitations need to be taken into consideration when examining the results of this rapid survey. First, it is vital to acknowledge the limitations associated with self-reported data, particularly data regarding qualitative assessments or judgements (often made by a single focal point). For some of the variables, it is not possible to compare self-reported responses with publicly available information due to the acute nature of the emergency and the limited availability of such data. While focal persons were encouraged to consult with other stakeholders, especially other humanitarian responders, the extent to which full-range consultation was implemented in each country is difficult to establish.

Another limitation is that most of the information provided relates to countries as a whole, thereby overlooking potentially significant variability within countries: for example, in rural versus urban areas or in remote versus central parts of a country.

Funding: None.

Competing interests: None declared. 


\section{Impact de la COVID-19 sur les services de santé mentale et de soutien psychosocial dans la Région de la Méditerranée orientale - résultats d'une évaluation rapide \\ Résumé}

Contexte: L'Organisation mondiale de la Santé a identifié la santé mentale comme faisant partie intégrante de la riposte à la COVID-19.

Objectifs : La présente étude avait pour objectif d'estimer l'impact de la pandémie de COVID-19 sur les services de prise en charge des troubles mentaux, neurologiques et liés à l'usage de substances psychoactives dans la Région de la Méditerranée orientale.

Méthodes : L'évaluation a été réalisée par le biais d'une enquête en ligne à laquelle ont participé les points focaux nationaux chargés de la santé mentale ; l'analyse des réponses a été réalisée entre juin et août 2020.

Résultats: Les services de santé mentale en milieux scolaire et professionnel ont été totalement ou partiellement perturbés dans plus de $70 \%$ des pays ayant notifié des données. Moins de $20 \%$ des pays de la Région ont signalé que les services de santé mentale pour les enfants et les adolescents ou pour les personnes âgées étaient pleinement opérationnels. Les principales raisons étaient les restrictions de voyage, la diminution du nombre de patients hospitalisés du fait de l'annulation des soins électifs, la diminution du volume des consultations externes en raison de l'absence de patients et des directives des autorités sanitaires concernant la fermeture des services de consultation externe. La majorité des pays (85\%) ont réagi en mettant en place des lignes d'assistance téléphonique pour les troubles mentaux et neurologiques à l'aide de la télémédecine/téléthérapie et d'interventions psychologiques numériques. Les États fragiles et touchés par des conflits dépendaient principalement de la mise en œuvre de mesures de prévention et de contrôle des infections dans les établissements de services de santé mentale et neurologique. Des lacunes ont été identifiées dans les domaines des comportements addictifs, de l'usage de substances psychoactives et de la recherche neurologique liée à la pandémie.

Conclusion: L'évaluation met en évidence la nécessité de renforcer les capacités de suivi des changements dans la prestation et l'utilisation des services, et documente les données concernant les pratiques efficaces dans divers contextes au cours des différentes phases de la pandémie afin de faciliter la prise de décisions éclairée concernant la nature et le calendrier des adaptations de la prestation de services.

$$
\begin{aligned}
& \text { أثر كوفيد-19 على خدمات الصحة النفسية والدعم النفسي الاجتحاعي في إقليم شرق المتوسط - نتائج تقييم سريع } \\
& \text { وفاء الصاوي، هبة فؤاد، خالد سعيد } \\
& \text { الخلفية: حددت منظمة الصحة العالمية الصحة النفسية بوصفها جزءًا لا يتجزأ من الاستجابة لكوفيد-19. } \\
& \text { الأهداف: هدفت هذه الدراسة إلى تقدير أثر جائحة كوفيد-19 على الخدمات المقدمة في مجال الاضطر ابات النفسية والعصبية والإدمانية في إقليم }
\end{aligned}
$$

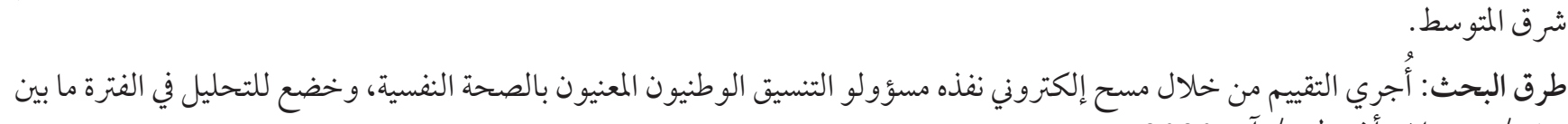

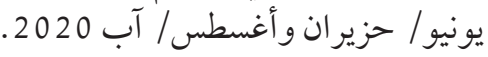

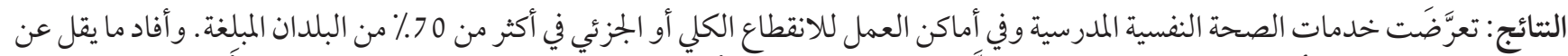

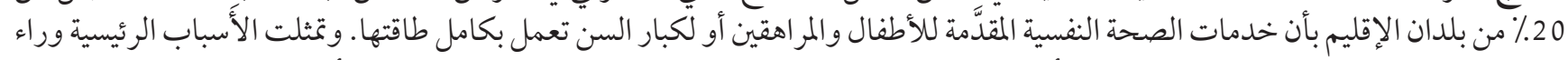

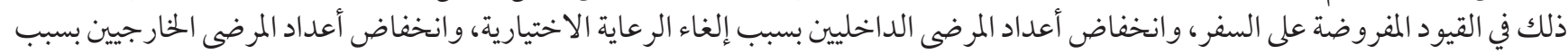

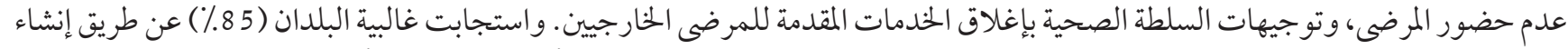

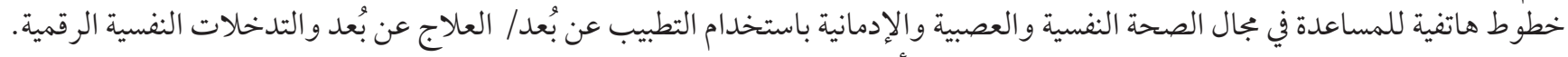

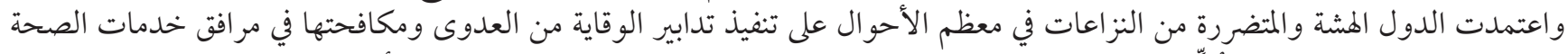

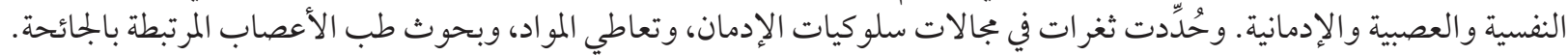

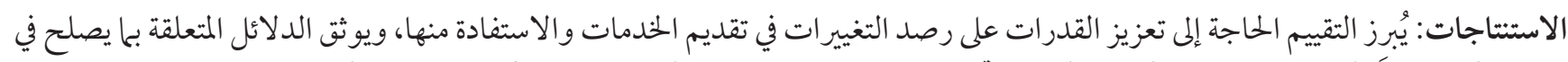

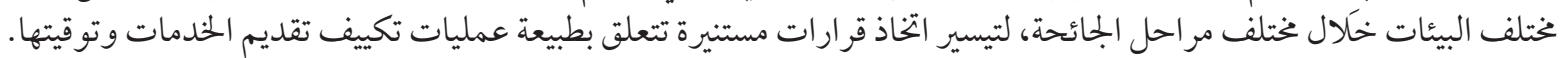




\section{References}

1. Archived: WHO Timeline - COVID-19. Geneva: World Health Organization; 2020 (https://www.who.int/news/item/27-04-2020who-timeline---covid-19, accessed 22 February 2021).

2. WHO Coronavirus (COVID-19) Dashboard. Geneva: World Health Organization; 2021 (https://covid19.who.int/, accessed 2 June 2021).

3. Qiu J, Shen B, Zhao M, Wang Z, Xie B, Xu Y. A nationwide survey of psychological distress among Chinese people in the COVID-19 epidemic: implications and policy recommendations. Gen Psychiatr. 2020;33(2):e100213. doi:10.1136/gpsych-2020-100213

4. Jahanshahi AA, Dinani MM, Madavani AN, Li J, Zhang SX. The distress of Iranian adults during the Covid-19 pandemic - more distressed than the Chinese and with different predictors. Brain Behav Immun. 2020;87:124-5. doi:10.1016/j.bbi.2020.04.081

5. Panchal N, Kamal R, Orgera K, Cox C, Garfield R, Hamel L, et al. The implications of COVID-19 for mental health and substance use. San Francisco, CA: KFF; 2020 (https://www.kff.org/coronaviruscovid-19/issue-brief/the-implications-of-covid-19-for-mentalhealth-and-substance-use/, accessed 5 January 2021).

6. Necho M, Belete A, Tsehay M, Zenebe Y. A meta-analysis of depressive symptoms among Ethiopian prisoners and a narrative description of its associated factors: a country based systematic review and meta-analysis study. BMC Psychiatry. 2020;20(281). doi:10.1186/s12888-020-02662-5

7. Bitew T. Prevalence and risk factors of depression in Ethiopia: a review. Ethiop J Health Sci. 2014;24(2):161-9. doi:10.4314/ejhs. v24i2.9

8. Abdel-Fattah HM, Hussein KA, Bahary H. Covid-19 impact on mental health of Egyptians patients. J Psychiatry Psychiatric Disorders. 2020;4: 87-93. doi:10.26502/jppd.2572-519X0095

9. Sani G, Janiri D, Di Nicola M, Janiri L, Ferretti S, Chieffo D. Mental health during and after the COVID-19 emergency in Italy. Psychiatry Clin Neurosci. 2020 Jun;74(6):372. doi:10.1111/pcn.13004

10. Policy brief: COVID-19 and the need for action on mental health. 13 May 2020. New York: United Nations; 2020 (https://unsdg. un.org/resources/policy-brief-covid-19-and-need-action-mental-health, accessed 5 January 2021).

11. Charlson F, van Ommeren M, Flaxman A, Cornett J, Whiteford H, Saxena S. New WHO prevalence estimates of mental disorders in conflict settings: a systematic review and meta-analysis. Lancet. 2019; 394: 240-8. doi:10.1016/So140-6736(19)30934-1

12. Interim briefing note addressing mental health and psychosocial aspects of COVID-19 outbreak (developed by the IASC's Reference Group on Mental Health and Psychosocial Support). Geneva: Inter-Agency Standing Committee; 2020 (https://interagencystandingcommittee.org/iasc-referencegroup-mental-health-and-psychosocial-support-emergency-settings/interim-briefing, accessed 5 January 2021).

13. The impact of COVID-19 on mental, neurological and substance use services: results of a rapid assessment. Geneva: World Health Organization; 2020. Licence: CC BY-NC-SA 3.0 IGO.

14. Health systems strengthening in countries of the Eastern Mediterranean Region: challenges, priorities and options for future action. Technical paper presented to the WHO Regional Committee for the Eastern Mediterranean, Fifty-ninth session, 2012. Cairo: WHO Regional Office for the Eastern Mediterranean; 2012 (www.emro.who.int/about-who/rc59/, accessed 5 December 2020).

15. Liu S, Yang L, Zhang C et al. Online mental health services in China during the COVID-19 outbreak. Lancet Psychiatry. 2020;7:e17-8. doi:10.1016/S2215-0366(20)30077-8.

16. Jimenez-Molina A, Franco P, Martinez V, Martinez P, Rojas G, Araya R. Internet-based interventions for the prevention and treatment of mental disorders in Latin America: a scoping review. Front Psychiatry. 2019;10:664. doi:10.3389/fpsyt.2019.00664

17. Naslund JA, Aschbrenner KA, Araya R, Marsch LA, Unützer J, Patel V, et al. Digital technology for treating and preventing mental disorders in low-income and middle-income countries: a narrative review of the literature. Lancet Psychiatry. 2017;4(6):486-500. doi:10.1016/S2215-0366(17)30096-2

18. Productivity Commission. Mental health, draft report. Canberra, ACT: Commonwealth of Australia; 2019.

19. Torous J, Wykes T. Opportunities from the coronavirus disease 2019 pandemic for transforming psychiatric care with telehealth. JAMA Psychiatry. 2020;11. doi:10.1001/jamapsychiatry.2020.1640

20. Gray B, Hanna F, Reifels L. The integration of mental health and psychosocial support and disaster risk reduction: a mapping and review. Int J Environ Res Public Health. 2020;17(6):1900. doi:10.3390/ijerph17061900 